\title{
Prevalence, Risk Factors and Outcome of Preterm Premature Rupture of Membranes at the Bamenda Regional Hospital
}

\author{
Dobgima Walter Pisoh ${ }^{1}$, Claude Hector Mbia1, William Ako Takang1, \\ Obelda Guiswe Beltus Djonsala1, Mbah Cypress Munje², Ascensius Achuo Mforteh1, \\ Dohbit Julius Sama ${ }^{3}$, Robert John Ivo Leke ${ }^{4}$
}

\author{
${ }^{1}$ Department of Clinical Sciences, Faculty of Health Sciences, University of Bamenda, Bambili, Cameroon \\ ${ }^{2}$ Bamenda Regional Hospital, Bamenda, Cameroon \\ ${ }^{3}$ Department of Obstetrics and Gynaecology, Faculty of Medicine and Biomedical Sciences, University of Yaounde I, \\ Yaounde, Cameroon \\ ${ }^{4}$ Catholic University of Cameroon, Bamenda, Cameroon \\ Email: ^dobpisoh@yahoo.co.uk
}

How to cite this paper: Pisoh, D.W., Mbia, C.H., Takang, W.A., Djonsala, O.G.B., Munje, M.C., Mforteh, A.A., Sama, D.J. and Leke, R.J.I. (2021) Prevalence, Risk Factors and Outcome of Preterm Premature Rupture of Membranes at the Bamenda Regional Hospital. Open Journal of Obstetrics and $G y$ necology, 11, 233-251.

https://doi.org/10.4236/ojog.2021.113023

Received: January 19, 2021

Accepted: March 8, 2021

Published: March 11, 2021

Copyright $\odot 2021$ by author(s) and Scientific Research Publishing Inc. This work is licensed under the Creative Commons Attribution International License (CC BY 4.0).

http://creativecommons.org/licenses/by/4.0/ (c) (i) Open Access

\begin{abstract}
Background: Preterm premature rupture of membranes (PPROM) is one of the most common complications of pregnancy. It is one of the leading identifiable cause of preterm deliveries, and an important cause of maternal and perinatal morbidity and mortality. The aim of this study was to determine the prevalence of PPROM, to identify its associated factors and to evaluate the early outcome (within $72 \mathrm{hrs}$ after delivery) following PPROM at the Bamenda Regional Hospital (BRH). Methods: A cross-sectional study was conducted in March and April 2020. Three hundred and eighty-seven women who delivered at the labour room of the BRH were included in this study. Interviewer-administered questionnaires were used to obtain data. The cases of PPROM were women who had lost amniotic fluid continuously before hospitalisation and whose gestational age was between 28 weeks +0 days and 36 weeks +6 days. Descriptive statistics followed by logistic regression analyses were conducted with level of significance set at $p$-value $<0.05$. Results: Among the 387 participants included in the study, 19 had PPROM giving a prevalence of $4.91 \%$. Of 57 preterm deliveries, PPROM accounted for $33.33 \%$ ( $\mathrm{n}=$ 19). The statistically significant independent factors associated with lower odds of PPROM were the age groups $20-29$ years $(\mathrm{aOR}=0.07,95 \%$ CI: 0.01 - $0.42, \mathrm{p}=0.003)$ and $\geq 30$ years $(\mathrm{aOR}=0.01,95 \%$ CI: $0.001-0.14, \mathrm{p}=0.001)$, and attending $\mathrm{ANC} \geq 4$ times $(\mathrm{aOR}=0.23,95 \% \mathrm{CI}: 0.06-0.84, \mathrm{p}=0.026)$. Whereas, having a multiple pregnancy $(\mathrm{aOR}=39.72,95 \% \mathrm{CI}: 7.19-219.33, \mathrm{p}$ $<0.001)$, urinary tract infection during pregnancy $(\mathrm{aOR}=104.86,95 \% \mathrm{CI}$ :
\end{abstract}


$12.25-897.90, \mathrm{p}<0.001)$, genital tract infections during pregnancy $(\mathrm{aOR}=$ 17.34, 95\% CI: $2.67-112.56, \mathrm{p}=0.003)$, and having a history of preterm delivery $(\mathrm{aOR}=27.65,95 \% \mathrm{CI}: 1.76-434.15, \mathrm{p}=0.018)$ were associated with a higher likelihood of PPROM. The study revealed that $10.53 \%(n=2)$ of women who had PPROM had an unfavourable outcome. Babies born by mothers who had PPROM were more likely to have an unfavourable outcome (OR $=14.44$, 95\% CI: 5.42 - 38.48, p < 0.001). Conclusion: Preterm premature rupture of membranes considerably causes perinatal morbidity and mortality, and thus optimum obstetric and medical care is essential for the reduction of the complications related to it.

\section{Keywords}

Preterm PROM, Maternal Outcome, Perinatal Outcome, Associated Factors

\section{Background}

Premature rupture of membranes (PROM) refers to the spontaneous rupture of the foetal membranes any time beyond the $28^{\text {th }}$ week of pregnancy but before the onset of labour [1]. When rupture of membranes occurs beyond the $37^{\text {th }}$ week but before the onset of labour, it is called term PROM (TPROM) and when it occurs before 37 completed weeks; it is called preterm PROM (PPROM) [1].

The incidence of PROM ranges from about five to ten percent of all deliveries [2]. The magnitude of PROM varies from country to country with a prevalence of $6.3 \%$ in Nigeria [3], 13.8\% in Uganda [4] and 7.4\% in Cameroon [5]. Preterm PROM occurs in approximately $3 \%$ of all pregnancies and causes about one third of preterm births [2]. The prevalence of PPROM ranges from $2.2 \%-4 \%$ in India [6] [7], 2.8\% in Canada [8], 3.1\% in Brazil [9], 3.3\% in Nigeria [10], to $4.1 \%$ in Egypt [11].

The cause of PPROM is multifactorial. It may be related to a structural defect in the membranes because of collagen deficiency or malformation, to the weakening of the membranes because of enzymatic destruction in inflammatory or infectious processes, and to sac exposure due to cervical incompetence. Many risk factors are associated with PPROM such as black race, low socioeconomic status of pregnant women, intrauterine infection at an early gestational age, vaginal bleeding during pregnancy, history of sexually transmitted infections, previous preterm delivery, polyhydramnios, multiple pregnancy, inadequate prenatal care and smoking during pregnancy, among others [12] [13]. Subclinical intrauterine infection has been implicated as a major aetiological factor in the pathogenesis and consequential maternal and neonatal morbidity in PPROM [14].

The burden of PROM ranges from maternal and neonatal morbidity and mortality to national economic loss due to drug expense, hospitalization, absence from the workplace and expense to the health professionals [15]. Complications 
of PPROM for the foetus and new born include prematurity, cord compression that leads to foetal distress, neonatal sepsis, respiratory distress syndrome (RDS), cord prolapse, placental abruption and risk of foetal and neonatal death [16]. Regarding the maternal risks, chorioamnionitis is the most common complication [15]. Other complications include; endometritis, retained placenta and haemorrhage requiring dilation and curettage, increased need for caesarean delivery, maternal sepsis, and maternal death [15] [17].

Currently, there is no effective way of preventing spontaneous rupture of foetal membranes with a consequent inability to control its incidence [10]. Prediction and prevention of PPROM would offer the best opportunity to prevent its complications [15]. The study of Monebenimp et al. [5] in Yaoundé, Cameroon revealed the prevalence of PROM to be 7.4\%, without specifying that of PPROM nor determining its risk factors and outcome. There is scarcity of data on prevalence, risk factors and outcome of PPROM in Bamenda, Cameroon. Hence, this study aims to determine the prevalence, the risk factors and to evaluate the outcome of PPROM among pregnant women attending the Bamenda Regional Hospital.

\section{Methods}

\subsection{Study Design and Setting}

This was a cross-sectional study conducted for 2 months from the 1st of March to the 30th of April 2020 at the Obstetrics and Gynaecology Department and the Neonatology Units of the Bamenda Regional Hospital (BRH). Bamenda is the capital of the Northwest Region (NWR) of Cameroon and has an estimated population of 394,000 inhabitants. The BRH is one of the major referral hospitals of the region. The Obstetrics and Gynaecology Department and the Neonatology Unit of the Paediatric department have both outpatient and inpatient services. The Obstetrics and Gynaecology Department has a gynaecology ward, an antenatal care unit, a family planning unit, a labour room, and a postnatal ward. The Paediatric department is made of the Neonatology Unit, the hospitalisation ward and outpatient consultation. The neonatology unit has eight incubators, 20 neonatal beds, two oxygen concentrators and a pure oxygen source.

\subsection{Study Population}

The study population comprised of all mothers who delivered at the BRH labour room during the data collection period, and their babies. All mothers who gave their consent to take part in the study were included in the study. Mothers whose gestational age could not be determined were excluded.

\subsection{Sample Size Calculation and Sampling Technique}

The sample size was calculated using Cochran's formula. Using an estimated proportion (p) of PPROM of $13.7 \%$ from a study by Addisu et al. in Ethiopia [18], our calculated minimum sample size was 182 mothers who delivered. The sam- 
pling technique was consecutive, involving all women who met the inclusion criteria during the data collection period.

\subsection{Study Procedure}

After obtaining ethical clearance (No 2020/0025H/UBa/IRB) to carry out the study from the Ethical Committee of the University of Bamenda and administrative authorization from the Director of the $\mathrm{BRH}$, mothers who met the inclusion criteria and gave their consent to the study were recruited. The recruitment process was carried out by the researcher daily during the data collection period.

The mothers were identified through the register of the labour room, traced to the postnatal ward or neonatology unit, and a face-to-face interview was carried out. Information got from each mother within the first 72 hours following delivery was entered onto a pre-tested questionnaire (Appendix). The signs and symptoms present prior to hospitalization, such as loss of fluid, blood loss, or uterine contractions, were retrospectively evaluated. Women who had a diagnosis of PROM were identified. All maternal diseases that occurred during pregnancy and those prior to pregnancy were investigated from the antenatal records and the admission file. Additional information regarding delivery details, maternal outcome and neonatal outcome were extracted from the admission files of both the mother and the baby if hospitalized and recorded on the questionnaire.

Cases of urinary tract infection (UTI) during pregnancy and the term at which they occurred were identified in antenatal records. Cases of genital tract infection were considered if the women had a history of non-white vaginal discharge, associated with foul odour, itching, or dyspareunia and documented in antenatal records. Per vaginal bleeding during pregnancy (threatened abortion or antepartum haemorrhage) was also considered if documented in antenatal records. For these pathologies, the term of pregnancy at which they occurred was determined.

PROM was considered when the woman had a history of continuous loss of amniotic fluid before hospitalization and/or documented by a Medical Doctor (General Practitioner or Obstetrician/Gynaecologist). This was recorded as PPROM if it occurred at a gestational age $<37$ weeks and TPROM if it occurred at a gestational age $\geq 37$ weeks. In Cameroon, rupture of membranes before 28 weeks gestation is considered as an abortion. The gestational age was assessed based on the last menstrual period or a first or second trimester ultrasound.

\subsection{Data Collection and Analysis}

The data was entered at the end of the collection process into a computer and analysed using the computer software Epi info version 7.2. Categorical variables were reported as frequencies and percentages, while numerical variables were summarized as means with their corresponding standard deviation (SD) and range. The measure of association was reported as odds ratios with corresponding $95 \%$ confidence interval and $p$-value of $<0.05$. After bivariate analysis, the factors that were statistically significant were entered for multivariate logistic re- 
gression analyses to determine the factors independently associated with PPROM among pregnant women admitted at the BRH. The level of significance was set at $\mathrm{p}$-value $<0.05$.

\section{Results}

Four hundred and three women were selected, of whom 11 refused to take part in the study and five women were excluded because their gestational age could not be determined. Thus, 387 participants were included in the study among which 34 had PROM, 19 had preterm PROM, and 57 had preterm deliveries.

\subsection{General Characteristics of the Study Population}

The ages of the participants ranged from 13 to 45 years with a mean age of 27.46 \pm 5.67 years. Most participants were in the age group $20-29$ years $(n=235$, $60.72 \%)$, were married ( $\mathrm{n}=304,78.55 \%)$, self-employed $(\mathrm{n}=182,47.03 \%)$ and had a secondary school level of education $(n=213,55.04 \%)$ (Table 1$)$.

Concerning the obstetric characteristics of the participants, majority of our participants were multigravida $(\mathrm{n}=233,60.21 \%)$, multipara $(\mathrm{n}=142,36.69 \%)$, had attended four or more antenatal consultations $(\mathrm{n}=301,77.78 \%)$, and had a singleton pregnancy $(\mathrm{n}=371,95.87 \%)$ (Table 2$)$.

\subsection{Prevalence of Preterm Premature Rupture of Membranes}

Among the 387 participants included in the study, the prevalence of PROM was

Table 1. Sociodemographic characteristics of participants.

\begin{tabular}{ccc}
\hline Variables & Frequency $(\mathrm{n}=387)$ & Percentage (\%) \\
\hline Maternal age (in years) & 18 & 4.65 \\
$<20$ & 235 & 60.72 \\
$20-29$ & 134 & 34.63 \\
$\geq 30$ & & \\
Marital status & 83 & 21.45 \\
Single & 304 & 78.55 \\
Married & & \\
Maternal occupation & 77 & 19.90 \\
Formal employment & 182 & 47.03 \\
Self-employment & 64 & 16.54 \\
Student & 64 & 16.54 \\
House wife & & \\
Level of education & 40 & 10.34 \\
Primary & 213 & 55.04 \\
Secondary & 134 & 34.63 \\
University & &
\end{tabular}

Formal employment $=$ teacher, nurse, lawyer, accountant, banker etc.; Self-employment $=$ farmer, tailor, hairdresser, trader etc. 
Table 2. Obstetric characteristics.

\begin{tabular}{ccc}
\hline Variables & Frequency $(\mathbf{n}=\mathbf{3 8 7})$ & Percentage (\%) \\
\hline Gravidity & 104 & 26.87 \\
Primigravida & 233 & 60.21 \\
Multigravida & 50 & 12.92 \\
Grand-multigravida & & \\
Parity & 123 & 32.82 \\
Nullipara & 109 & 28.17 \\
Primipara & 142 & 36.69 \\
Multipara & 9 & 2.33 \\
Grand-multipara & & \\
Number of ANC & 86 & 22.22 \\
$<4$ & 301 & 77.78 \\
$\geq 4$ & & 95.87 \\
Type of Pregnancy & 371 & 4.13 \\
Singleton & 16 & \\
Multiple & & \\
\hline
\end{tabular}

ANC $=$ Antenatal consultations.

8.79\% $(\mathrm{n}=34)$ and the prevalence of preterm PROM was $4.91 \%(\mathrm{n}=19)$. The proportion of PPROM was $33.33 \%$ of all preterm deliveries. The gestational age at which PPROM occurred ranged from 28 to 36 weeks, with a mean of 33 weeks +2 days \pm 2 weeks +2 days.

\subsection{Factors Associated with Preterm Premature Rupture of Membranes}

After multivariate logistic regression analysis, women belonging to the age groups 20 - 29 years $(\mathrm{aOR}=0.07,95 \% \mathrm{CI}: 0.01-0.42, \mathrm{p}=0.003)$ and $\geq 30$ years $(\mathrm{aOR}=$ $0.01,95 \%$ CI: $0.001-0.14, \mathrm{p}=0.001$ ) were less likely to have PPROM. Women who attended ANC $\geq 4$ times were less likely to experience PPROM compared to their counterparts who attended $<4$ ANC $(\mathrm{aOR}=0.23,95 \% \mathrm{CI}: 0.06-0.84, \mathrm{p}=$ 0.026) (Table 3(a)).

Whereas, women with multiple pregnancies $(\mathrm{aOR}=39.72,95 \%$ CI: 7.19 219.33, $\mathrm{p}<0.001)$, who had UTI during pregnancy $(\mathrm{aOR}=104.86,95 \% \mathrm{CI}: 12.25$ - 897.90, $\mathrm{p}<0.001)$, who had genital tract infections during pregnancy $(\mathrm{aOR}=$ 17.34, 95\% CI: $2.67-112.56, \mathrm{p}=0.003)$ and who had a history of preterm delivery $(\mathrm{aOR}=27.65,95 \% \mathrm{CI}: 1.76-434.15, \mathrm{p}=0.018)$ had higher odds of developing PPROM (Table 3(a) and Table 3(b)).

\subsection{Early Outcome Following Preterm Premature Rupture of Membranes}

Mode of delivery 
Table 3. Factors associated with PPROM on bivariate and multivariate logistic regression analyses.

(a)

\begin{tabular}{|c|c|c|c|c|c|c|}
\hline VARIABLES & $\begin{array}{l}\text { PPROM } \\
\text { N (\%) }\end{array}$ & $\begin{array}{c}\text { NO PPROM } \\
\text { N (\%) }\end{array}$ & OR $(95 \% \mathrm{CI})$ & $\mathrm{P}$-value & aOR $(95 \% \mathrm{CI})$ & $P$-value \\
\hline \multicolumn{7}{|c|}{ Maternal age (in years) } \\
\hline$<20$ & $4(22.22)$ & $14(77.78)$ & Reference & & Reference & \\
\hline $20-29$ & $11(4.68)$ & $224(95.32)$ & $0.17(0.05-0.61)$ & $0.006^{*}$ & $0.07(0.01-0.42)$ & $0.003^{*}$ \\
\hline$\geq 30$ & $4(2.99)$ & $130(97.01)$ & $0.11(0.02-0.48)$ & $0.003^{*}$ & $0.01(0.001-0.14)$ & $0.001^{*}$ \\
\hline \multicolumn{7}{|l|}{ Marital status } \\
\hline Married & $13(4.28)$ & $291(95.72)$ & Reference & & & \\
\hline Single & $6(7.23)$ & $77(92.77)$ & $1.74(0.64-4.74)$ & 0.275 & l & \\
\hline \multicolumn{7}{|c|}{ Employment status } \\
\hline Employed & $11(4.25)$ & $248(95.75)$ & Reference & & & \\
\hline Unemployed & $8(6.25)$ & $120(93.75)$ & $1.50(0.59-3.84)$ & 0.393 & l & \\
\hline \multicolumn{7}{|c|}{ Level of education } \\
\hline Primary & $2(5.00)$ & $38(95.00)$ & Reference & & & \\
\hline Secondary & $15(7.04)$ & $198(92.96)$ & $1.44(0.32-6.55)$ & 0.638 & l & \\
\hline University & $2(1.49)$ & $132(98.51)$ & $0.29(0.04-2.11)$ & 0.221 & l & \\
\hline \multicolumn{7}{|c|}{ PV bleeding in pregnancy } \\
\hline Yes & $3(27.27)$ & $8(72.73)$ & $8.44(2.04-34.85)$ & $0.003^{*}$ & $9.21(0.94-90.25)$ & 0.057 \\
\hline No & $16(4.26)$ & $360(95.74)$ & Reference & & Reference & \\
\hline \multicolumn{7}{|c|}{$\begin{array}{l}\text { Consumed alcohol } \\
\text { during pregnancy }\end{array}$} \\
\hline Yes & $2(4.26)$ & $45(95.74)$ & $0.84(0.19-3.78)$ & 0.825 & l & \\
\hline No & $17(5.00)$ & $323(95.00)$ & Reference & & & \\
\hline \multicolumn{7}{|l|}{ Number of ANC } \\
\hline$<4$ & $10(11.63)$ & $76(88.37)$ & Reference & & Reference & \\
\hline$\geq 4$ & $9(2.99)$ & $292(97.01)$ & $0.23(0.09-0.59)$ & $0.002^{*}$ & $0.23(0.06-0.84)$ & $0.026^{*}$ \\
\hline \multicolumn{7}{|c|}{ Type of pregnancy } \\
\hline Singleton & $14(3.77)$ & $357(96.23)$ & Reference & & Reference & \\
\hline Multiple & $5(31.25)$ & $11(68.75)$ & $11.59(3.55-37.87)$ & $<0.001^{*}$ & $39.72(7.19-219.33)$ & $<0.001^{*}$ \\
\hline
\end{tabular}

*Significant P-value; $\mathrm{N}$ = frequency; $\mathrm{CI}=$ Confidence interval; $\mathrm{OR}=$ Odds ratio (bivariate logistic analysis); aOR = Adjusted Odds ratio (multivariate logistic analysis); $\mathrm{PPROM}=$ Preterm premature rupture of membranes; $\mathrm{PV}=$ Per vaginal; $\mathrm{ANC}=$ Antenatal consultation.

(b)

\begin{tabular}{|c|c|c|c|c|c|c|}
\hline VARIABLES & $\begin{array}{c}\text { PPROM } \\
\text { N (\%) }\end{array}$ & $\begin{array}{c}\text { NO PPROM } \\
\text { N (\%) }\end{array}$ & OR (95\% CI) & P-value & aOR $(95 \% \mathrm{CI})$ & $\mathrm{P}$-value \\
\hline \multicolumn{7}{|c|}{ UTI in pregnancy } \\
\hline Yes & $4(50.00)$ & $4(50.00)$ & $24.26(5.53-106.48)$ & $<0.001^{*}$ & $104.86(12.25-897.90)$ & $<0.001^{*}$ \\
\hline No & $15(3.96)$ & $364(96.04)$ & Reference & & Reference & \\
\hline Genital infection in pr & & & & & & \\
\hline
\end{tabular}




\section{Continued}

\begin{tabular}{|c|c|c|c|c|c|c|}
\hline Yes & $4(25.00)$ & $12(75.00)$ & $7.93(2.29-27.49)$ & $0.001^{*}$ & $17.34(2.67-112.56)$ & $0.003^{*}$ \\
\hline No & $15(4.04)$ & $356(95.96)$ & Reference & & Reference & \\
\hline \multicolumn{7}{|c|}{ Gravidity } \\
\hline$<2$ & $6(5.77)$ & $98(94.23)$ & $0.96(0.23-4.00$ & 0.954 & I & \\
\hline $2-4$ & $10(4.29)$ & $223(95.71)$ & $0.70(0.19-2.65)$ & 0.602 & I & \\
\hline$\geq 5$ & $3(6.00)$ & $47(94.00)$ & Reference & & & \\
\hline \multicolumn{7}{|c|}{ Parity } \\
\hline$<2$ & $13(5.51)$ & $223(94.49)$ & $0.47(0.05-4.00)$ & 0.486 & I & \\
\hline $2-4$ & $5(3.52)$ & $137(96.48)$ & $0.29(0.03-2.79)$ & 0.285 & I & \\
\hline$\geq 5$ & $1(11.11)$ & $8(88.89)$ & Reference & & & \\
\hline \multicolumn{7}{|c|}{ Past history of PROM } \\
\hline Yes & $3(27.27)$ & $8(72.73)$ & $8.44(2.04-34.85)$ & $0.003^{*}$ & $3.18(0.23-44.04)$ & 0.388 \\
\hline No & $16(4.26)$ & $360(95.74)$ & Reference & & Reference & \\
\hline \multicolumn{7}{|c|}{ Past history of abortion } \\
\hline Yes & $4(5.33)$ & $71(94.67)$ & $1.12(0.36-3.46)$ & 0.850 & I & \\
\hline No & $15(4.81)$ & $297(95.19)$ & Reference & & & \\
\hline \multicolumn{7}{|c|}{ Past history of preterm delivery } \\
\hline Yes & $3(37.50)$ & $5(62.50)$ & $13.61(2.98-62.01)$ & $0.001^{*}$ & $27.65(1.76-434.15)$ & $0.018^{*}$ \\
\hline No & $16(4.22)$ & $363(95.78)$ & Reference & & Reference & \\
\hline \multicolumn{7}{|c|}{ Past history of Caesarean section } \\
\hline Yes & $3(5.17)$ & $55(94.83)$ & $1.06(0.30-3.78)$ & 0.918 & I & \\
\hline No & $16(4.86)$ & $313(95.14)$ & Reference & & & \\
\hline
\end{tabular}

${ }^{*}$ Significant $\mathrm{P}$-value; $\mathrm{N}$ = frequency; $\mathrm{CI}=$ Confidence interval; $\mathrm{OR}=$ Odds ratio (bivariate logistic analysis); aOR = Adjusted Odds ratio (multivariate logistic analysis); / = not included in multivariate analysis due to a P-value $>0.05$ on bivariate analysis; PPROM = Preterm premature rupture of membranes; UTI = Urinary tract infections.

Among the 19 participants who had preterm PROM, 13 (68.42\%) had spontaneous onset of labour and vaginal delivery, 5 (26.32\%) underwent a caesarean section (CS), and one (5.26\%) had an induced vaginal delivery. The major indications for CS were cord prolapse $(n=3,60 \%)$, acute foetal distress $(n=1,20 \%)$ and breech presentation $(\mathrm{n}=1,20 \%)$.

\section{* Foetal/neonatal outcome}

Among the babies delivered by women who had PPROM, 57.89\% $(\mathrm{n}=11)$ had an unfavourable outcome (either born alive but admitted in the neonatal ward, stillbirth, neonatal death, fifth minute Apgar score $<7$ or birth weight $<2500 \mathrm{~g}$ ). The mean birth weight was $2436.84 \pm 618.43 \mathrm{~g}$ with a range of $1100-3200 \mathrm{~g}$. The perinatal loss rate among babies born by women with PPROM was $10.53 \%(\mathrm{n}=$ 2).

Babies born by women who had PPROM were significantly more likely to be admitted in the neonatal ward ( $\mathrm{OR}=11.37,95 \% \mathrm{CI}: 4.26-30.35, \mathrm{p}<0.001)$, to 
be stillborn (OR $=20.39,95 \%$ CI: $1.23-339.31, \mathrm{p}=0.036)$, to have a fifth minute Apgar score $<7(\mathrm{OR}=5.12,95 \% \mathrm{CI}: 1.33-19.78, \mathrm{p}=0.018)$ to have a birthweight $<2500 \mathrm{~g}(\mathrm{OR}=22.94,95 \% \mathrm{CI}: 8.24-63.86, \mathrm{p}<0.001)$, and to have an unfavourable outcome in general (OR $=14.44,95 \%$ CI: $5.42-38.48, \mathrm{p}<0.001)$ compared to their counterparts who were born by women without PPROM (Table 4).

* Acute causes of neonatal morbidity among babies born from mothers with PPROM

The reasons for hospitalisation among the nine babies admitted in the neonatology unit following PPROM include low birth weight $(\mathrm{n}=6,66.67 \%)$, birth asphyxia $(\mathrm{n}=1,11.11 \%)$, neonatal infection $(\mathrm{n}=1,11.11 \%)$ and respiratory distress syndrome $(\mathrm{n}=1,11.11 \%)$. Babies born following PPROM were more likely to be hospitalised for low birth weight (OR $=16.51,95 \%$ CI: $5.21-52.32, \mathrm{p}<$ 0.001) (Table 5).

Table 4. Foetal/neonatal outcome and association with PPROM.

\begin{tabular}{|c|c|c|c|c|}
\hline VARIABLES & $\begin{array}{l}\text { PPROM } \\
\text { N (\%) }\end{array}$ & $\begin{array}{c}\text { NO PPROM } \\
\text { N (\%) }\end{array}$ & OR (95\% CI) & $\mathrm{P}$-value \\
\hline \multicolumn{5}{|l|}{ Still birth } \\
\hline Yes & $1(5.26)$ & $1(0.27)$ & $20.39(1.23-339.31)$ & $0.036^{*}$ \\
\hline No & $18(94.74)$ & $367(99.73)$ & Reference & \\
\hline \multicolumn{5}{|c|}{ Admission in neonatal ward } \\
\hline Yes & $9(47.37)$ & $27(7.34)$ & $11.37(4.26-30.35)$ & $<0.001^{*}$ \\
\hline No & $10(52.63)$ & $341(92.66)$ & Reference & \\
\hline \multicolumn{5}{|l|}{ Neonatal death } \\
\hline Yes & $1(5.26)$ & $5(1.36)$ & $4.03(0.45-36.35)$ & 0.214 \\
\hline No & $18(94.74)$ & $363(98.64)$ & Reference & \\
\hline \multicolumn{5}{|l|}{$1^{\text {st }}$ minute Apgar } \\
\hline$<7$ & $2(10.53)$ & $17(4.62)$ & $2.43(0.52-11.38)$ & 0.259 \\
\hline$\geq 7$ & $17(89.47)$ & $351(95.38)$ & Reference & \\
\hline \multicolumn{5}{|l|}{$5^{\text {th }}$ minute Apgar } \\
\hline$<7$ & $3(15.79)$ & $13(3.53)$ & $5.12(1.33-19.78)$ & $0.018^{*}$ \\
\hline$\geq 7$ & $16(84.21)$ & $355(96.47)$ & Reference & \\
\hline \multicolumn{5}{|c|}{ Birth weight (in grams) } \\
\hline$<2500$ & $10(52.63)$ & $17(4.62)$ & $22.94(8.24-63.86)$ & $<0.001^{*}$ \\
\hline$\geq 2500$ & $9(47.37)$ & $351(95.38)$ & Reference & \\
\hline \multicolumn{5}{|l|}{ Outcome } \\
\hline Favourable & $8(42.11)$ & $336(91.30)$ & Reference & \\
\hline Unfavourable & $11(57.89)$ & $32(8.70)$ & $14.44(5.42-38.48)$ & $<0.001^{*}$ \\
\hline
\end{tabular}

*Significant P-value; $\mathrm{N}=$ Frequency; $\mathrm{CI}$ = Confidence interval; OR = Odds ratio; PPROM = Preterm premature rupture of membranes. 
Table 5. Acute causes of neonatal morbidity among babies born from mothers with PPROM.

\begin{tabular}{ccccc}
\hline VARIABLES & $\begin{array}{c}\text { PPROM } \\
\mathrm{n}(\%)\end{array}$ & $\begin{array}{c}\text { NO PPROM } \\
\mathrm{n}(\%)\end{array}$ & OR (95\% CI) & P-value \\
\hline Birth asphyxia & $1(5.26)$ & $10(2.72)$ & $1.98(0.24-16.39)$ & 0.523 \\
Yes & $18(94.74)$ & $358(97.28)$ & Reference & \\
No & & & & \\
Low birth weight & $6(31.58)$ & $10(2.72)$ & $16.51(5.21-52.32)$ & $<0.001^{*}$ \\
Yes & $13(68.42)$ & $358(97.28)$ & Reference & \\
No & & & & \\
Neonatal infection & $1(5.26)$ & $4(1.09)$ & $5.07(0.54-47.62)$ & 0.156 \\
Yes & $18(94.74)$ & $364(98.91)$ & Reference & \\
No & & & & \\
Respiratory distress syndrome & $1(5.26)$ & $3(0.82)$ & 6.77 (0.67 - 68.31) & 0.105 \\
Yes & $18(94.74)$ & $365(99.18)$ & Reference & \\
No & & & & \\
\hline
\end{tabular}

${ }^{*}$ Significant $\mathrm{P}$-value; $\mathrm{N}=$ Frequency; $\mathrm{CI}=$ Confidence interval; $\mathrm{OR}=$ Odds ratio; $\mathrm{PPROM}=$ Preterm premature rupture of membranes.

\section{Maternal Outcome}

Among the 19 women with PPROM, 2 (10.53\%) had an unfavourable outcome (one had post-partum endometritis, and the other had a retained placenta with postpartum haemorrhage. Among the 368 women without PPROM, 1 $(0.27 \%)$ had an unfavourable outcome (post-partum endometritis) following a caesarean delivery not related to PROM. Women who had PPROM were more likely to develop postpartum endometritis ( $\mathrm{OR}=20.39,95 \%$ CI: $1.23-339.31, \mathrm{p}$ $=0.036)$, and less likely to have a favourable outcome (OR $=0.02,95 \% \mathrm{CI}: 0.002$ $-0.27, \mathrm{p}=0.003)($ Table 6).

\section{Discussion}

\subsection{Prevalence of Preterm Premature Rupture of Membranes}

The prevalence of PPROM among women admitted at the Bamenda Regional Hospital was $4.91 \%$ and it accounted for one-third of all preterm births. Our prevalence is close to 4.1\% reported by Abouseif et al. [11] in Egypt and to 4\% reported by Rajan et al. [7] in India. Our prevalence is higher than the 3.3\% reported by Okeke et al. [10] in Nigeria, the $2.8 \%$ reported by Bouvier et al. [8] in Canada and that reported by Hackenhaar et al. [9] in Brazil of 3.1\%. The diversity in the definitions of PPROM in the various studies could explain some of these differences. The higher rate of PPROM in our study could also be explained by the fact that the BRH is a main referral hospital of the North-West Region of Cameroon, to which complicated cases are usually referred. Furthermore, the low rate in Brazil and Canada may be due to better socioeconomic 
Table 6. Maternal outcome and association with PPROM.

\begin{tabular}{ccccc}
\hline VARIABLES & $\begin{array}{c}\text { PPROM } \\
\mathrm{n}(\%)\end{array}$ & $\begin{array}{c}\text { NO PPROM } \\
\mathrm{n}(\%)\end{array}$ & OR (95\% CI) & P-value \\
\hline Postpartum endometritis & & & & \\
Yes & $1(5.26)$ & $1(0.27)$ & $20.39(1.23-339.31)$ & $\mathbf{0 . 0 3 6 ^ { * }}$ \\
No & $18(94.74)$ & $367(99.73)$ & Reference & \\
Retained placenta & & & Undefined & \\
Yes & $1(5.26)$ & $0(0.00)$ & & \\
No & $18(94.74)$ & $368(100.00)$ & & \\
Maternal outcome & & & $0.003^{*}$ \\
Favourable & $17(89.47)$ & $367(99.73)$ & $0.002-0.27)$ & \\
Unfavourable & $2(10.53)$ & $1(0.27)$ & Reference & \\
\hline
\end{tabular}

*Significant P-value; $\mathrm{N}=$ Frequency; $\mathrm{CI}=$ Confidence interval; $\mathrm{OR}=$ Odds ratio; $\mathrm{PPROM}=$ Preterm premature rupture of membranes; Favourable outcome $=$ No maternal complication; Unfavourable outcome $=$ Presence of maternal complication.

status, regular antenatal check-ups, prompt identification and treatment of vaginal infections and other risk factors in developed countries compared to developing countries. The study conducted by Byonanuwe et al. [5] in Uganda revealed a prevalence of $7.5 \%$, which is higher than our findings. This discrepancy may be attributed to the contextual differences in the study settings. The study conducted in Uganda was in a rural setup and in the only well-equipped facility with which referral of pregnant women with PROM is made.

\subsection{Factors Associated with Preterm Premature Rupture of Membranes}

Women belonging to the age groups 20 - 29 years and $\geq 30$ years were statistically less likely to develop PPROM compared to those aged $<20$ years in this study. This finding differs from what was found in the study done by Hackenhaar et al. [9] in Brazil, where women aged $\geq 30$ years were instead more likely to develop PPROM. This discrepancy might be due to difference in the study population and study setting.

Not attending ANC decreases the chance of identifying risk factors and providing appropriate interventions towards prevention of PPROM. Our finding revealed that women who attended four or more ANCs were less likely to have PPROM as compared to women who attended ANC less than four times. This finding is in line with studies conducted in India and Uganda [19] [20]. However, in the study done by Assefa et al. [21] in Ethiopia, the number of ANCs was not significantly associated with PROM. This discrepancy might be because of a difference in study design. The study done in Ethiopia was a case-control study and ANC coverage in both groups was similarly high.

In our study, participants who had multiple pregnancies were statistically significantly more likely to develop PPROM than those who had singleton pregnancies. This is similar to the findings of Mercer et al. [22] in the USA and 
Bouvier et al. [8] in Canada.

A history of preterm delivery was statistically associated with the occurrence of PPROM, which is similar to the findings from literature from Canada, China and the USA [8] [23] [24]. However, the study by Assefa et al. [21] in Ethiopia revealed no association between history of preterm delivery and PPROM.

Our study revealed that women who had UTI during pregnancy were statistically more likely to develop PPROM. This finding is similar to the findings of Addisu et al. [18] in Ethiopia but contrary to the findings of Hackenhaar et al. [9] in Brazil. UTIs are potential reservoirs for bacteria that cross to the vagina and ascend through the cervical canal to the membranes where they cause localized inflammation. The bacteria produce several proteolytic enzymes such as collagenase and gelatinase that can cause local weakening of the membranes. The subsequent prostaglandin production resulting from localized inflammation leads to occult contractions with increased shearing stress at the internal cervical os resulting in PROM.

Women who had a genital tract infection during pregnancy in this study were statistically more likely to have PPROM. This is in line with studies conducted in Ethiopia, Uganda and Egypt [18] [20] [25] whereas Hackenhaar et al. [9] in Brazil found no association. Some genital bacteria produce enzymes such as proteases, phospholipases, and collagenases, which cause membrane weakness and rupture [2]. These genital tract infections are often diagnosed and treated late and so can cause PROM in some cases, whereas treatment completion for these infections in some hospitals will prevent PROM.

Per vaginal bleeding during pregnancy (threatened abortion or antepartum haemorrhage) was not statistically associated with PPROM in our study on multivariate analysis, even though there was an association on crude analysis. This is contrary to the findings of Hackenhaar et al. [9] and Addisu et al. [18]. This difference might be due to a low frequency of per vaginal bleeding during pregnancy among our study participants.

On bivariate analysis, a history of PROM was statistically associated with the occurrence of PPROM but there was no statistically significant association on multivariate analysis, which is contrary to the findings of Addisu et al. [18] and Bouvier et al. [8] in Canada who had a significant association between a history of PROM and occurrence of PPROM. Obstetric problems are usually recurrent in nature and failure of our study to show an association between a history of PROM and occurrence of PROM might be because of few women with a history of PROM within our study sample.

No statistical association was found between the marital status, employment status, level of education, alcohol consumption, gravidity, parity, history of abortion and history of caesarean delivery and the occurrence of PPROM.

\subsection{Outcome Following Preterm Premature Rupture of Membranes}

Foetal/Neonatal Outcome 
Most (57.89\%) of babies born following PPROM in our study had an unfavourable outcome. This is slightly lower than $61.3 \%$ reported by Abouseif et al. [11] in Egypt. It is however higher than 28.6\% reported by Fishman et al. [26] in Zambia. The higher rates in our study and the study done in Egypt may be because they were done in referral hospitals that received complicated cases of PPROM and had a higher number of low birth weight babies.

This study revealed a perinatal loss among babies born following PPROM of $10.53 \%$, which is higher than $8.9 \%$ reported by Okeke et al. [10] in Nigeria and 3.29\% reported by Mohan et al. [6] in India. However, this rate is lower when compared to $14.3 \%$ reported by Abouseif et al. [11] in Egypt probably because there was a high rate of low birth weight.

The proportion of babies born following PPROM that were admitted in the neonatal ward in our study was $47.37 \%$ which is close to $47 \%$ reported by Abouseif et al. [11]. Higher values of $65.3 \%$ and $75.8 \%$ were reported in other studies [27] [28]. The higher rate of admission compared to our study was because their studies were performed on preterm babies, therefore more problems and a higher rate of admission compared to our study that included infants born at a wider range of gestational ages.

The study of Sultana et al. [29] in Pakistan revealed a proportion of low birth weight babies to be $35.5 \%$. In our study, a higher proportion of babies born following PPROM (52.63\%) had low birth weight. Other studies had higher values (79.3\%) than what we found [11].

Our study also showed that $15.79 \%$ of babies born following PPROM had a fifth minute APGAR less than 7 . This differs from 30.6\% reported by Sultana et al. [29]. This difference is probably because of the fact that Sultana et al. had a much larger sample.

\section{- Maternal Outcome}

In our study, $10.53 \%$ of women who had PPROM developed an unfavourable outcome (had a complication). The reported morbidities were postpartum endometritis and retained placenta. We did not have any case of chorioamnionitis. The study of Okeke et al. [10] in Nigeria revealed a much higher proportion of maternal morbidity (20\%). This discrepancy is because of the possible lack of effectiveness of prophylactic antibiotics, as noted in the study of Okeke et al. [10] and low socio-economic status of patients involved.

\section{Study Limitations}

The diagnosis of PROM was made based on clinical evaluation, and no other confirmatory tests were done except for ultrasound in some cases. We had no control over the methods used in measuring birth weight and determining the Apgar score of the neonates. This research might be subjected to recall bias, since participants might not have remembered and reported past events correctly.

\section{Conclusion}

The prevalence of PPROM at the Bamenda Regional Hospital is similar to what 
is found in other low and middle-income countries. The identified risk factors of PPROM are maternal age less than 20 years, less than four ANCs attended, multiple pregnancy, urinary or genital tract infection during pregnancy, and history of preterm delivery. It is essential to screen for the modifiable factors during antenatal care to prevent PPROM.

\section{Declarations}

\section{Ethics Approval and Consent to Take Part}

Ethical clearance was got from the Institutional Review Board of the Faculty of Health Sciences of the University of Bamenda and administrative authorisations were got from the Regional Delegation of Public Health for the North West Region and from the Director of the Bamenda Regional Hospital. Before administering the questionnaire, the study was explained to each participant in detail, and a written consent was got. Those who were not literate placed thumbprints after accepting to have fully understood the study.

\section{Availability of Data and Materials}

The datasets used and/or analysed during the current study are available from the corresponding author on a reasonable request.

\section{Authors' Contributions}

DWP, MCH, and RJIL were involved in the study's design and drafted the protocol. DWP, MCH, OGD and RJIL analysed the data. MCH, DWP and DSJ drafted and finalized the manuscript for publication. TAW, MCM, AAM, DJS and RJIL edited the manuscript. All authors contributed to the writing of the paper and approved the final version.

\section{Acknowledgements}

We express our heartfelt thanks to participants for their willingness to take part in the study, without which this research would not be possible.

\section{Conflicts of Interest}

The authors declare no conflicts of interest regarding the publication of this paper.

\section{References}

[1] Dutta, D.C. (2015) DC Dutta's Textbook of Obstetrics Including Perinatology and Contraception. 8th Edition, Jaypee Brothers Medical Publisher's Ltd., New Delhi, 369. https://doi.org/10.5005/jp/books/12540

[2] Gibbs, R., Karlan, B., Haney, A. and Nygaard, I. (2008) Danforth's Obstetrics and Gynecology. 10th Edition, Lippincott Williams \& Wilkins, Philadelphia.

[3] Emechebe, C.I., Njoku, C.O., Anachuma, K. and Odofa, U. (2015) Determinants and Complications of Pre-Labour Rupture of Membranes (PROM) at the University of Calabar Teaching Hospital (UCTH), Calabar, Nigeria. Scholars Journal of Applied 
Medical Sciences, 3, 1912-1917.

[4] Byonanuwe, S., Nzabandora, E., Nyongozi, B., Pius, T., Ayebare, D.S., Atuheire, C., et al. (2020) Predictors of Premature Rupture of Membranes among Pregnant Women in Rural Uganda: A Cross-Sectional Study at a Tertiary Teaching Hospital. International Journal of Reproductive Medicine, 2020, Article ID: 1862786. https://doi.org/10.1155/2020/1862786

[5] Monebenimp, F., Makudjou, T., Mve, K.V. and Kago, I. (2012) Competence of Health Care Providers on Care of New-Borns at Birth in a Level-1 Health Facility in Yaoundé, Cameroon. The Pan African Medical Journal, 11, 45.

[6] Mohan, S.S., Thippeveeranna, C., Singh, N.N. and Singh, L.R. (2017) Analysis of Risk Factors, Maternal and Foetal Outcome of Spontaneous Preterm Premature Rupture of Membranes: A Cross Sectional Study. International Journal of Reproduction, Contraception, Obstetrics and Gynecology, 6, 3781-3787. https://doi.org/10.18203/2320-1770.ijrcog20173623

[7] Rajan, R. and Menon, V. (2016) Preterm Premature Rupture of Membranes: Correlates and Pregnancy Outcome in a Tertiary Care Setting. International Journal of Research in Medical Sciences, 4, 3310-3316. https://doi.org/10.18203/2320-6012.ijrms20162285

[8] Bouvier, D., Forest, J.-C., Blanchon, L., Bujold, E., Pereira, B., Bernard, N., et al. (2019) Risk Factors and Outcomes of Preterm Premature Rupture of Membranes in a Cohort of 6968 Pregnant Women Prospectively Recruited. Journal of Clinical Medicine, 8, 1987. https://doi.org/10.3390/jcm8111987

[9] Hackenhaar, A.A., Albernaz, E.P. and Fonseca, T.M. (2014) Preterm Premature Rupture of the Fetal Membranes: Association with Sociodemographic Factors and Maternal Genitourinary Infections. Jornal de Pediatria, 90, 197-202. https://doi.org/10.1016/j.jped.2013.08.003

[10] Okeke, T.C., Enwereji, J.O., Okoro, O.S., Adiri, C.O., Ezugwu, E.C. and Agu, P.U. (2014) The Incidence and Management Outcome of Preterm Premature Rupture of Membranes (PPROM) in a Tertiary Hospital in Nigeria. American Journal of Clinical Medicine Research, 2, 14-17. https://doi.org/10.12691/ajcmr-2-1-4

[11] Abouseif, H.A., Mansour, A.F., Hassan, S.F. and Sabbour, S.M. (2018) Prevalence and Outcome of Preterm Premature Rupture of Membranes (PPROM) among Pregnant Women Attending Ain Shams Maternity Hospital. The Egyptian Journal of Community Medicine, 36, 99-107. https://doi.org/10.21608/ejcm.2018.11055

[12] Medina, T.M. and Hill, D.A. (2006) Preterm Premature Rupture of Membranes: Diagnosis and Management. American Family Physician, 73, 659-664.

[13] Savitz, D.A., Blackmore, C.A. and Thorp, J.M. (1991) Epidemiology Characteristics of Preterm Delivery: Etiology Heterogeneity. American Journal of Obstetrics and Gynecology, 164, 467-471. https://doi.org/10.1016/S0002-9378(11)80001-3

[14] Hyagriv, N.S. and Timothy, P.C. (2005) Preterm Premature Rupture of Membranes: Diagnosis, Evaluation and Management Strategies. BJOG, 11, 32-37. https://doi.org/10.1111/j.1471-0528.2005.00582.x

[15] Gabbe, S.G., Niebyl, J.R. and Simpson, J.L. (2007) Obstetrics: Normal and Problem Pregnancies. 5th Edition, Churchill Livingstone, London.

[16] Dars, S., Malik, S. and Samreen, I. (2014) Maternal Morbidity and Perinatal Outcome in Preterm Premature Rupture of Membranes before 37 Weeks' Gestation. Pakistan Journal of Medical Sciences, 30, 626-629.

https://doi.org/10.12669/pjms.303.4853

[17] Mercer, B.M. (2012) Antibiotics in the Management of PROM and Preterm Labor. 
Obstetrics and Gynecology Clinics of North America, 39, 65-76. https://doi.org/10.1016/j.ogc.2011.12.007

[18] Addisu, D., Melkie, A. and Biru, S. (2020) Prevalence of Preterm Premature Rupture of Membrane and Its Associated Factors among Pregnant Women Admitted in Debre Tabor General Hospital, North West Ethiopia: Institutional-Based CrossSectional Study. Obstetrics and Gynecology International, 2020, Article ID: 4034680. https://doi.org/10.1155/2020/4034680

[19] Choudhary, M., Rathore, S.B., Chowdhary, J. and Garg, S. (2015) Pre and Post Conception Risk Factors in PROM. International Journal of Research in Medical Sciences, 3, 2594-2598. https://doi.org/10.18203/2320-6012.ijrms20150797

[20] Kaye, D. (2001) Risk Factors for Preterm Premature Rupture of Membranes at Mulago Kampala Uganda. East African Medical Journal, 78, 65-69.

https://doi.org/10.4314/eamj.v78i2.9090

[21] Assefa, N.E., Berhe, H., Girma, F., Berhe, K., Berhe, Y.Z., Gebrehet, G., et al. (2018) Risk Factors of Premature Rupture of Membranes in Public Hospitals at Mekele City, Tigray, a Case Control Study. BMC Pregnancy and Childbirth, 18, 386. https://doi.org/10.1186/s12884-018-2016-6

[22] Mercer, B.M., Crocker, L.G., Pierce, W.F. and Sibai, B.M. (1993) Clinical Characteristics and Outcome of Twin Gestation Complicated by Preterm Premature Rupture of the Membranes. American Journal of Obstetrics and Gynecology, 168, 14671473. https://doi.org/10.1016/S0002-9378(11)90783-2

[23] Zhou, Q., Zhang, W., Xu, H., Liang, H., Ruan, Y., Zhou, S., et al. (2014) Risk Factors for Preterm Premature Rupture of Membranes in Chinese Women from Urban Cities. International Journal of Gynecology \& Obstetrics, 127, 3-5.

https://doi.org/10.1016/j.ijgo.2014.06.020

[24] Edem, E., Carol, A., Robert, W. and Atef, M. (1993) Risks for Premature Rupture of Amniotic Membranes. International Journal of Epidemiology, 22, 495-503. https://doi.org/10.1093/ije/22.3.495

[25] Tarek, K.A., Sahar, N.M., Hamida, A.E. and Amal, A.A. (2012) Cervicovaginal Infection during Pregnancy and Its Relation to Preterm Pre-Labour Rupture of Membranes. Journal of American Science, $\mathbf{8}$.

[26] Fishman, S.G. and Gelber, S.E. (2012) Evidence for the Clinical Management of Chorioamnionitis. Seminars in Fetal \& Neonatal Medicine, 17, 46-50. https://doi.org/10.1016/j.siny.2011.09.002

[27] Yang, L.C., Donald, R.T., Kaufman, Hume, R., Calhour, B. and Howard, H.K. (2004) Maternal and Fetal Outcomes of Spontaneous Preterm Premature Rupture of Membranes. The Journal of the American Osteopathic Association, 104, 537-542.

[28] Nabhan, A.F., Elhelaly, A. and Elkadi, M. (2014) Antibiotic Prophylaxis in Prelabor Spontaneous Rupture of Fetal Membranes at or beyond 36 Weeks of Pregnancy. International Journal of Gynecology \& Obstetrics, 124, 59-62. https://doi.org/10.1016/j.ijgo.2013.07.018

[29] Sultana, S., Ishtiaq, S., Malik, U., Akhai, A.Z. and Nadeem, K. (2019) Maternal and Perinatal Outcome in Preterm Prelabor Rupture of Membranes. Pakistan Journal of Surgery, 35, 73-77. 


\section{List of Abbreviations}

ANC: Antenatal consultations;

BRH: Bamenda Regional Hospital;

NWR: North West Region;

PPROM: Preterm premature rupture of membranes;

PROM: Premature rupture of membranes;

SD: Standard Deviation;

TPROM: Term premature rupture of membranes;

UTI: Urinary tract infections.

\section{Appendix}

\section{QUESTIONNAIRE}

Study No Date of interview.

SECTION A: SOCIO-DEMOGRAPHIC VARIABLES

1) Age of the mother (in years)

2) Marital status. $1=$ Single $\square 2=$ Married

3) Maternal occupation.

$1=$ Formal employment $\square \quad 3=$ House-wife

$2=$ Self-employed $4=$ Student

4) Maternal level of education.

$1=$ No education

$3=$ Secondary

$2=$ Primary School

$4=$ University level $\square$

SECTION B: CURRENT OBSTETRIC HISTORY

5) Did you smoke cigarette during this pregnancy? $1=\mathrm{No} \square \quad 2=$ Yes $\square$

6) Did you consume alcohol during this pregnancy? $1=\mathrm{No} \square \quad 2=$ Yes $\square$

7) How many times have you been pregnant before (gravid formula)?........

8) What is the date of your last menstrual period?

9) Did you lose liquor continuously before the onset of labour contractions?

$1=\mathrm{No}$

$$
2=\text { Yes }
$$

10) If yes, how was it?

$1=$ Clear/pale yellow and watery

$3=$ Bloody

$2=$ Green-brown and watery

$4=$ White and thick

11) What was the gestational age at loss of liquor

12) Number of ANCs attended.

13) Type of pregnancy.

$1=$ Single $\square \quad 2$ = Multiple

14) Do you have a history of vaginal bleeding during current pregnancy? $1=$ No $\square \quad 2=$ Yes $\square$

15) If yes to the above question, in which trimester was it?

$1=$ First $2=$ Second $3=$ Third 
16) Did you have a urinary tract infection during current pregnancy?

$1=$ No $\square \quad 2=$ Yes $\square$

17) If yes to the above question, in which trimester was it? (only second and third were considered in analysis)

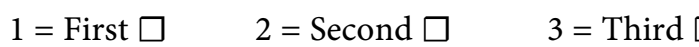

18) Did you have a genital infection during current pregnancy?

$1=$ No $\square \quad 2$ = Yes

19) If yes to the above question, in which trimester was it? (Only second and third were considered in analysis)

$$
1=\text { First } \square \quad 2=\text { Second } \square \quad 3=\text { Third } \square
$$

SECTION C: PAST OBSTETRIC HISTORY

20) Do you have a history of abortion?

$1=$ No $\square \quad 2=$ Yes $\square$

21) Do you have a history of Caesarean section?

$1=$ No $\square \quad 2=$ Yes

22) Did you lose liquor continuously before the onset of labour in your previous pregnancies (History of premature rupture of membranes)?

$1=$ No $\square \quad 2=$ Yes $\square$

23) Did you have labour contractions more than one month before your due date in previous pregnancies (History of preterm delivery)?

$1=$ No $\square \quad 2=$ Yes $\square$

SECTION D: DELIVERY DETAILS

24) Preterm delivery?

$1=$ No $\square \quad 2=$ Yes

25) Mode of delivery

$1=$ Spontaneous vaginal delivery $\square \quad 3=$ Caesarean section $\square$

$2=$ Instrumental delivery $\square \quad 4=$ Induced vaginal delivery

26) If Caesarean section, what was the indication?

$1=$ Foetal distress $\square \quad 3=$ Failed induction $\square \quad 5=$ Other

$2=$ Breech presentation $\square 4=$ Non progress of labour (Dystocia)

SECTION E: FOETAL OUTCOME

27) Birth weight (to the nearest 10 grams)

28) APGAR Score. First minute. .Fifth minute............

29) Stillbirth?

$1=$ No

$$
2=\text { Yes } \square
$$

30) Neonatal death?

$1=\mathrm{No}$

$2=$ Yes

31) Admission to neonatology unit?

$1=$ No $2=$ Yes

32) If yes, what for?

$1=$ Neonatal infection $\square \quad 3=$ Birth asphyxia $\square \quad 5=$ Other......

2 = Respiratory distress syndrome $\square \quad 4$ = Low birth weight

SECTION F: MATERNAL OUTCOME 
33) Maternal complication?

$1=$ No $\square \quad 2=$ Yes $\square$

34) If yes, which?

$1=$ Chorioamnionitis $\square$

$3=$ Endometritis $\square$

$5=$ Other

$2=$ Retained placenta $\square$

$4=$ Sepsis 